\title{
Article
}

\section{Particle Flow Simulation of the Strength and Failure Characteristics of a Layered Composite Rock-Like Sample with a Single Hole}

\author{
Guozhu Wang ${ }^{1}{ }^{\circledR}$, Yu Wang ${ }^{1, *}$, Lei Song ${ }^{1}$, Hao Shi ${ }^{1}$, Mingwei Zhang ${ }^{1}$, Guotao Yuan ${ }^{1}$, Qiangguo Xu ${ }^{2}$, \\ Guangda $\mathrm{Xu}^{2}$, Weiqian Zhang ${ }^{2}$ and Jianjun Gao ${ }^{2}$
}

1 State Key Laboratory for Geomechanics \& Deep Underground Engineering, China University of Mining and Technology, Xuzhou 221116, China; guozhuwang@cumt.edu.cn (G.W.); leisong@cumt.edu.cn (L.S.); shihao@cumt.edu.cn (H.S.); zhangmingwei@cumt.edu.cn (M.Z.); guotaoyuan@cumt.edu.cn (G.Y.)

2 Zhaolou Coal Mine, Yanmei Heze Energy and Chemical Company Ltd., Heze 274705, China; qiangguoxu@cumt.edu.cn (Q.X.); guangdaxu@cumt.edu.cn (G.X.); weiqianzhang@cumt.edu.cn (W.Z.); jianjungao@cumt.edu.cn (J.G.)

* Correspondence: yuwang@cumt.edu.cn

Citation: Wang, G.; Wang, Y.; Song, L.; Shi, H.; Zhang, M.; Yuan, G.; Xu, Q.; Xu, G.; Zhang, W.; Gao, J. Particle Flow Simulation of the Strength and Failure Characteristics of a Layered Composite Rock-Like Sample with a Single Hole. Symmetry 2021, 13, 1132. https://doi.org/10.3390/sym13071132

Academic Editor: Sergei Alexandrov

Received: 23 April 2021

Accepted: 22 June 2021

Published: 24 June 2021

Publisher's Note: MDPI stays neutral with regard to jurisdictional claims in published maps and institutional affiliations.

Copyright: (c) 2021 by the authors. Licensee MDPI, Basel, Switzerland. This article is an open access article distributed under the terms and conditions of the Creative Commons Attribution (CC BY) license (https:// creativecommons.org/licenses/by/ $4.0 /)$.

\begin{abstract}
Layered rock masses with holes are common in nature. Their mechanical behavior plays an important role in the safety and stability of engineering structures. However, previous studies have concentrated on a single lithological layer, and few studies have reported on the mechanical behavior of layered rock masses with holes. Based on the concept of symmetry, uniaxial compression tests and numerical simulations were performed on rock-like specimens with three layers and a hole in the interlayer. The hole was in the center of the sample and was symmetrical up and down. The influence of the thickness and strength of the interlayer on the mechanical behavior and failure processes of the layered rock masses with holes was investigated. The results show that the peak strength and elastic modulus were associated with the thickness and strength of the interlayer. Three failure modes were observed in the specimens, which were not only related to the thickness and strength of the interlayer, but also affected by the presence of the hole. When the thickness of the interlayer is small, mainly a single failure mode was observed (tensile failure or shear failure). However, when the interlayer was thick, the failure mode was tension-shear mixed failure. The failure mechanism of the specimens was primarily crack propagation at the edge of the hole. These research results can provide a basis for site selection, and the design of surrounding rock protection and support parameters, and thus have important practical significance for improving surrounding rock stability and ensuring construction safety.
\end{abstract}

Keywords: layered composite rock-like sample; single hole; uniaxial compression; strength and failure characteristics; particle flow simulation

\section{Introduction}

A layered rock mass is a composite rock mass with continuous parallel layers of varying thickness, which possesses strong symmetry, and is often encountered in the process of tunnel, roadway, drilling and other engineering construction. Because it contains bedding, joints and other weak surfaces, its mechanical properties are anisotropic, and its failure mechanism is quite different from that of other rock masses [1-6]. Therefore, research on the mechanical properties and failure mechanism of layered rock masses can provide a basis for engineering site selection, and the design of surrounding rock protection and support parameters, and thus has important practical significance for improving surrounding rock stability and ensuring construction safety.

Through theoretical analysis [7-9], similarity simulation [10,11], numerical simulation [12-15], and acoustic emission testing [16-19], a large number of scholars have systematically studied layered composite rock masses from the perspective of macro-deformation 
and micro-damage. A layered rock mass is generally regarded as a transversely isotropic rock mass, and the most influential criterion is the Jaeger failure criterion based on the relationship between the interlayer shear force and bedding dip angle [7]. Later, Duveau and Shao [20] modified the Jaeger criterion, proposing the generalized Jaeger criterion. Tien and Kuo [8] studied the mechanical properties of layered rock masses using simulation materials, summarized four typical failure modes of layered rock masses, and gave the relevant failure criteria. Nasseri et al. [21] and Zhang et al. [22] conducted uniaxial compression tests and triaxial compression tests on Himalayan schist and sandstone, respectively, and studied the influence law of the bedding dip angle on the corresponding rock mass strength. Xu et al. [23] analyzed the effect of bedding angle on crack growth under dynamic loading, and found that dynamic cracks are prone to deflection at bedding boundaries. Wasantha et al. [16] found that the relationship between acoustic emission (AE) energy and axial strain rate under different bedding angles reflects the influence of bedding angle on initial crack initiation, dissipated energy and strain energy. The above research mainly focuses on the mechanical properties, deformation characteristics, failure criteria and damage and fracture process of layered composite rock masses, and the achievements enrich and deepen the understanding of layered composite rock masses.

However, as a common cross-sectional form in underground engineering, circular holes such as tunnels, roadways and boreholes also affect the stability of engineering rock masses and attract the attention of researchers. Sammis et al. [24-26] studied the fracture law of rock with holes and theoretically studied the damage evolution mechanism of rock. However, because an appropriate theoretical model is not yet fully mature, research on the deformation and fracture law of rock with holes is mainly carried out by model testing. Lajtai [27] carried out biaxial compression tests on gypsum material to determine the interaction mechanism between hole collapse and cracks and the internal fracture unit. Carter et al. [28] studied the fracture mode of rock with a single circular cavity, and found that the evolution process includes the generation of main tensile cracks, secondary cracks and shear cracks. Subsequently, a group of scholars carried out many laboratory tests on brittle rock, such as granite [29], marble [30] and sandstone [31], with prefabricated holes. Under compression, a crack in a specimen with voids begins to form in the tensile stress concentration area around the voids, and then gradually propagates along the loading direction or grain boundary to the end of the specimen or the weak part of the boundary, and the mechanical parameters of the specimen are affected by the distribution and diameters of the voids. However, the influence of layered rock masses is not considered in the above studies, which cannot truly reflect the geological environment of the actual engineering structure, and the universality of the research results is weakened to a certain extent.

Therefore, in this paper, the uniaxial compression test and numerical simulation of layered rock mass with holes are carried out by combining the two research elements of prefabricated holes and layered rock mass. Combined with the mechanical properties and crack propagation law of layered rock mass with holes, the surrounding rock stability of circular cross-section structure in layered rock mass is discussed. The results can provide reference for the design and construction of underground rock engineering, the support of excavation chamber and the stability analysis of surrounding rock.

\section{Model Establishment and Micro-Parameter Calibration}

\subsection{Brief Introduction of the Particle Flow Program}

PFC is a discrete element code proposed by Cundall et al. [32] to simulate the motion and interaction between circular particles. PFC has been gradually developed into an effective tool to solve complex solid mechanics and particle flow problems. In the field of rock mechanics, PFC can form a sample by sticking adjacent particles together, which can be regarded as brittle rock samples with elastic and fracture characteristics. The relationship between particles is simple, that is, the motion between particles is defined by Newton's second law. In addition, there is no need to define a constitutive model in PFC. 
As long as micro-parameters such as the friction coefficient, stiffness and bond strength are defined, macro-mechanical parameters such as the elastic modulus and peak strength can be calculated by the program. PFC provides two bonding models, contact bonding and parallel bonding, to describe the bonding characteristics between particles. Among them, the contact bond can only transfer the force, while the parallel bond is similar to the cement effect between particles, which can transfer the force and moment between particles. Because both mechanical behaviors described by the above two bonding models may occur in rock, such as in brittle materials, the two bonding models are used simultaneously in this study [33].

Within PFC, the effect of parallel bonding on the mechanical behavior of particles is analogous to adding cementitious materials between particles that can transfer force and moment. Parallel bonding can be modelled as a group of elastic springs with constant normal stiffness and shear stiffness that are evenly distributed over the contact plane, where the center point is located at the contact point. After a bond is formed, the relative motion of the contact produces a force and moment in the cementitious material. The force and moment acting on the two contact surfaces are related to the maximum normal stress and shear stress that the bonding material can bear. If these maximum stresses exceed the corresponding bond strength, the parallel bond breaks; then, the bond material and its accompanying forces, moments and stiffness are removed from the model, and only the linear model will be used. The constitutive model of parallel bonding is shown in Figure 1.

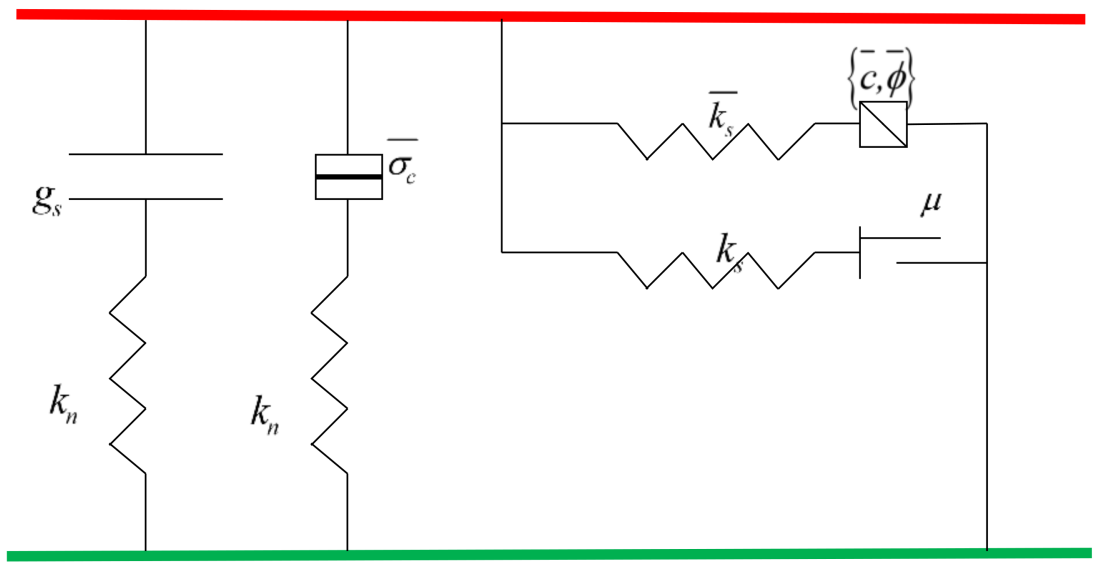

(a) Parallel bonding

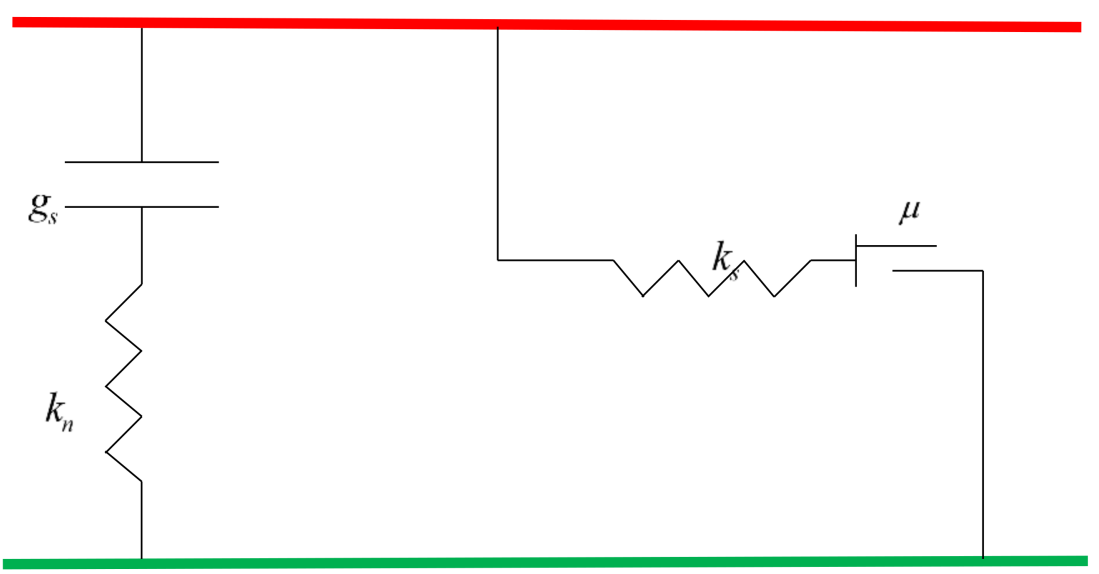

(b) Bond failure

Figure 1. Parallel bonded constitutive model.

The parallel bond model is a combination of two constitutive models. One model is linear, does not provide any resistance relative rotation, and the slip in the tangential 
direction is mainly regulated by friction. The other provides a bond force to resist forces and moments, and has a tensile strength. The shear strength in the tangential direction conforms to the Mohr-Coulomb criterion. When the load is excessively large, bond failure occurs, and the parallel bond model becomes equivalent to the linear model. The stress expression of parallel bond model is

$$
\begin{array}{r}
\bar{\sigma}=\frac{\overline{F_{n}}}{\bar{A}}+\bar{\beta} \frac{\left\|\overline{M_{b}}\right\| \bar{R}}{\bar{I}} \\
\bar{\tau}=\frac{\left\|\overline{F_{s}}\right\|}{\bar{A}}+\left\{\begin{array}{l}
0 \\
\bar{\beta} \frac{\left|\overline{M_{t}}\right| \bar{R}}{\bar{J}}
\end{array}\right. \\
\bar{\beta} \in[0,1]
\end{array}
$$

where $\overline{F_{n}}$ is the normal force at the contact point; $F_{s}$ is the tangential force at the contact point; $\overline{M_{b}}$ and $\overline{M_{t}}$ are the bending moment and torque in the contact plane, respectively; $\bar{R}$ is the particle radius used in the calculation; $\bar{A}$ is the cross-sectional area; $\bar{I}$ is the moment of inertia; $\bar{J}$ is the polar moment of inertia; and $\bar{\beta}$ is the moment contribution coefficient.

\subsection{Modelling}

To study the failure characteristics and mechanical properties of layered rock masses with holes with respect to the height and strength of the interlayer, two models of soft rock intercalated with hard rock (SHS) and hard rock intercalated with soft rock (HSH) with holes were established. The width of the sample $(70 \mathrm{~mm})$ and the height of the sample $(210 \mathrm{~mm})$ are shown in Figure 2a. By changing the height of the intermediate layer $\left(h_{m}\right)$, samples with height ratios $\left(h_{r}\right)$ varying from $0 \%$ to $100 \%$ were generated, and the variation interval was $10 \%$. A total of 20 samples were made. SHS- $h_{r}$ and $\mathrm{HSH}-h_{r}$ represent the samples with different interlayer height ratios, as shown in Figure 2. For example, $\mathrm{HSH}-30 \%$ represents the sample of hard rock intercalated with soft rock with holes whose interlayer height accounts for $30 \%$ of the sample height. The samples with height ratios of $0 \%$ and $100 \%$ are pure hard rock with a single hole and pure soft rock with a single hole, respectively. The parallel bond model was used in the soft rock and hard rock, and the linear contact model was used in the bond interface between the soft rock and hard rock. A numerical model of the layered rock mass with holes is shown in Figure $2 b$.

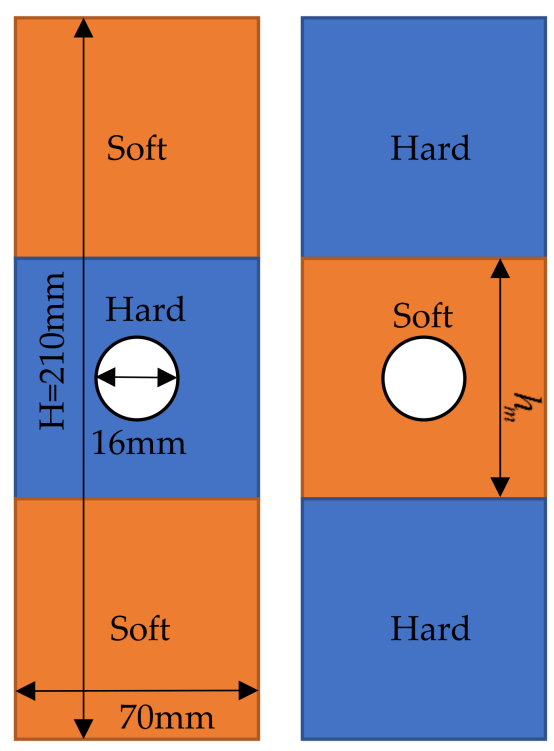

(a) Model diagram

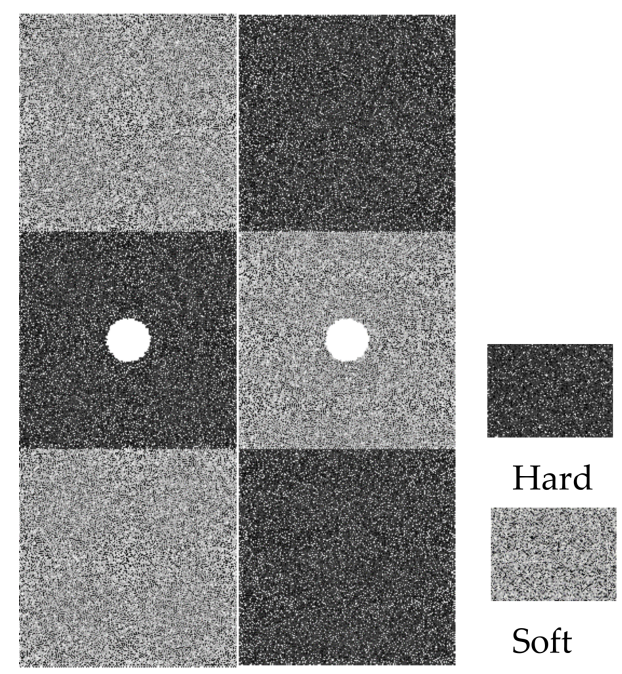

(b) Numerical model

Figure 2. Schematic diagram and numerical model diagram of a layered model with a single hole. 


\subsection{Micro-Parameter Calibration}

In the established numerical model, the macro-mechanical behavior of a specimen is determined by micro-parameters, such as the parallel bonding modulus, linear contact modulus of the particles, bonding stiffness ratio, and tangential and normal bonding strengths. Differences in these micro-parameters will lead to different macro-mechanical characteristics, such as the elastic modulus and peak strength. To obtain the same macrobehavior of the stress-strain curve as determined from the laboratory testing, the model micro-parameters should be calibrated to reflect the mechanical behavior of a laboratory test sample. Considering the discreteness of rock, similar materials are selected to simulate soft rock and hard rock. The mix proportion and corresponding basic mechanical parameters of the soft rock and hard rock used in this work are shown in Tables 1 and 2. The compressive strength of soft and hard rock are based on the engineering rock classification standard [34], in which a compressive strength $\geq 30 \mathrm{MPa}$ corresponds to hard rock, and $<30 \mathrm{MPa}$ corresponds to soft rock. Therefore, the similar materials used in this study can be extended to real rocks to a certain extent. In the process of material pouring, special attention should be given to the interlayer pouring method, to ensure not only that there is a certain adhesive force between layers, but also that the interface of adjacent layers is clear and that the layer thickness is uniform. Therefore, each surface of the customized transparent mould is marked to control the thickness of the pouring layer. In addition, attention should be given to the duration of the pouring process. If the interval time is too short, two adjacent layers will mix into each other, which will lead to an unclear interface between layers; if the interval time is too long, the bonding force between layers is too weak, and the rock sample will be broken along the bedding plane during the drilling process. After several attempts, the interval time between layers is determined to be $1 \mathrm{~h}$. Therefore, in the process of pouring, each layer is poured and maintained for approximately $1 \mathrm{~h}$ before pouring the next layer, so that the poured model not only has a certain strength, but also avoids mixing with the next layer of newly poured material mixture. To enhance the contrast between layers, black ink is added to the hard rock materials. Four samples, SHS- $0 \%$, SHS- $30 \%$, $\mathrm{HSH}-30 \%$ and $\mathrm{HSH}-0 \%$, were made to verify the correctness of the micro-parameters used in the numerical model.

Table 1. Mix proportions of rock-like materials.

\begin{tabular}{|c|c|c|c|}
\hline Type & Water/(kg m $\left.{ }^{-3}\right)$ & Cement/(kg m $\left.{ }^{-3}\right)$ & Quartz Sand $/\left(\mathrm{kg} \mathrm{m}^{-3}\right)$ \\
\hline Hard & 310 & 360 & 1450 \\
\hline Soft & 330 & 320 & 1450 \\
\hline
\end{tabular}

Table 2. Physical and mechanical parameters of rock-like materials.

\begin{tabular}{ccccc}
\hline Type & $\begin{array}{c}\text { Compressive } \\
\text { Strength/MPa }\end{array}$ & $\begin{array}{c}\text { Tensile } \\
\text { Strength/MPa }\end{array}$ & $\begin{array}{c}\text { Elastic } \\
\text { Modulus/GPa }\end{array}$ & Poisson's Ratio \\
\hline Hard & 310 & 360 & 1450 & 0.16 \\
Soft & 37.26 & 3.22 & 13.35 & 0.12 \\
\hline
\end{tabular}

All the tests described in this paper are carried out with a YNS2000 testing machine (Figure 3). The test procedure is as follows: first, put the sample on the testing machine; second, add steel cushion blocks at both end of the sample to reduce the impact of end friction on the test results; finally, apply the uniaxial loading with the testing machine until the sample is damaged. The displacement control loading method is adopted in the test, the loading rate is $0.004 \mathrm{~mm} / \mathrm{s}$, and the axial displacement and load data are automatically collected by a computer during loading. To simulate the laboratory loading tests more realistically and effectively, displacement controlled loading is also used in the simulation, that is, simulated loading is carried out by moving the upper and lower walls, and the loading rate is $0.05 \mathrm{~m} / \mathrm{s}$. 


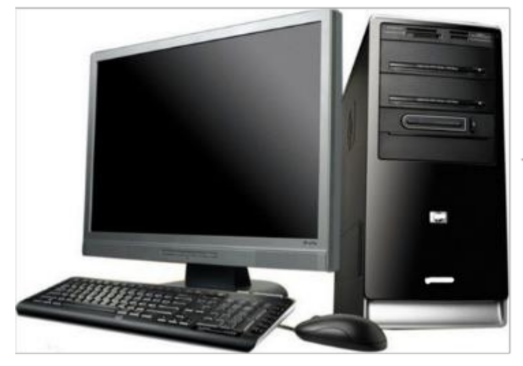

Loading controlling system and data acquisition
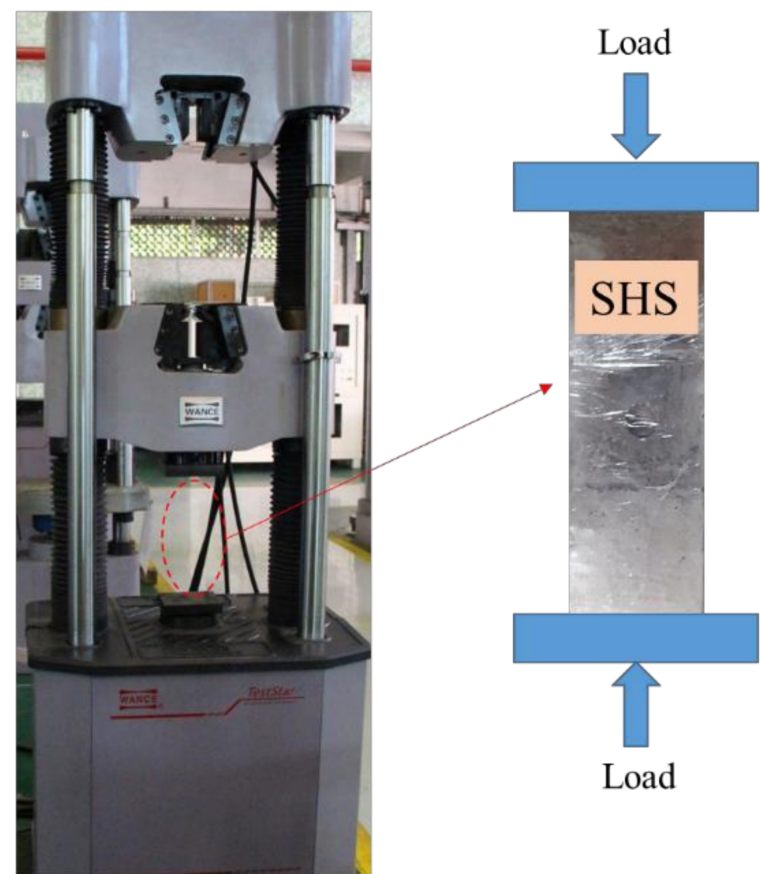

Platen

Platen

Loading instrument

Figure 3. Testing system (YNS2000 servo-controlled) for the rock-like specimens.

First, through repeated debugging of the "trial and error method" [35,36], a group of micro-parameters that can reflect the macro-mechanical properties of soft rock and hard rock are obtained, as shown in Table 3. To further verify the rationality of the selected micro-parameters, laboratory uniaxial compression tests and numerical simulation loading tests of layered specimens with a single hole are carried out, and the mechanical parameters are compared, as shown in Table 4. From the test and numerical simulation results, it can be seen that the stress-strain curve and failure mode of the simulated samples are in good agreement with the test results, that is, the micro-parameters used in the numerical model can accurately characterize the macro-mechanical properties of layered rock samples with a single hole.

Table 3. Micro-parameters of the numerical model.

\begin{tabular}{cccc}
\hline Parameters & Value & Parameters & Value \\
\hline Minimum particle size $(\mathrm{mm})$ & 0.3 & Friction coefficient & 0.8 \\
Maximum particle size $(\mathrm{mm})$ & 0.45 & Parallel bond tensile strength $(\mathrm{MPa})$ & $6.25(15.3)$ \\
Density $\left(\mathrm{kg} \cdot \mathrm{m}^{-3}\right)$ & 2590 & Parallel bond cohesion $(\mathrm{MPa})$ & $16.0(39.2)$ \\
Porosity & $0.15(0.1)$ & Parallel bond friction angle $\left(^{\circ}\right)$ & 45 \\
Contact bond modulus $(\mathrm{GPa})$ & 5.9 & Parallel bond modulus $(\mathrm{GPa})$ & $7.0(9.0)$ \\
Contact bond stiffness ratio & 1.0 & Parallel bond stiffness ratio & 3.0 \\
\hline
\end{tabular}

Note: the values in brackets indicate the micro-parameters of the hard rock materials. 
Table 4. Comparison of numerical simulation and experimental results.

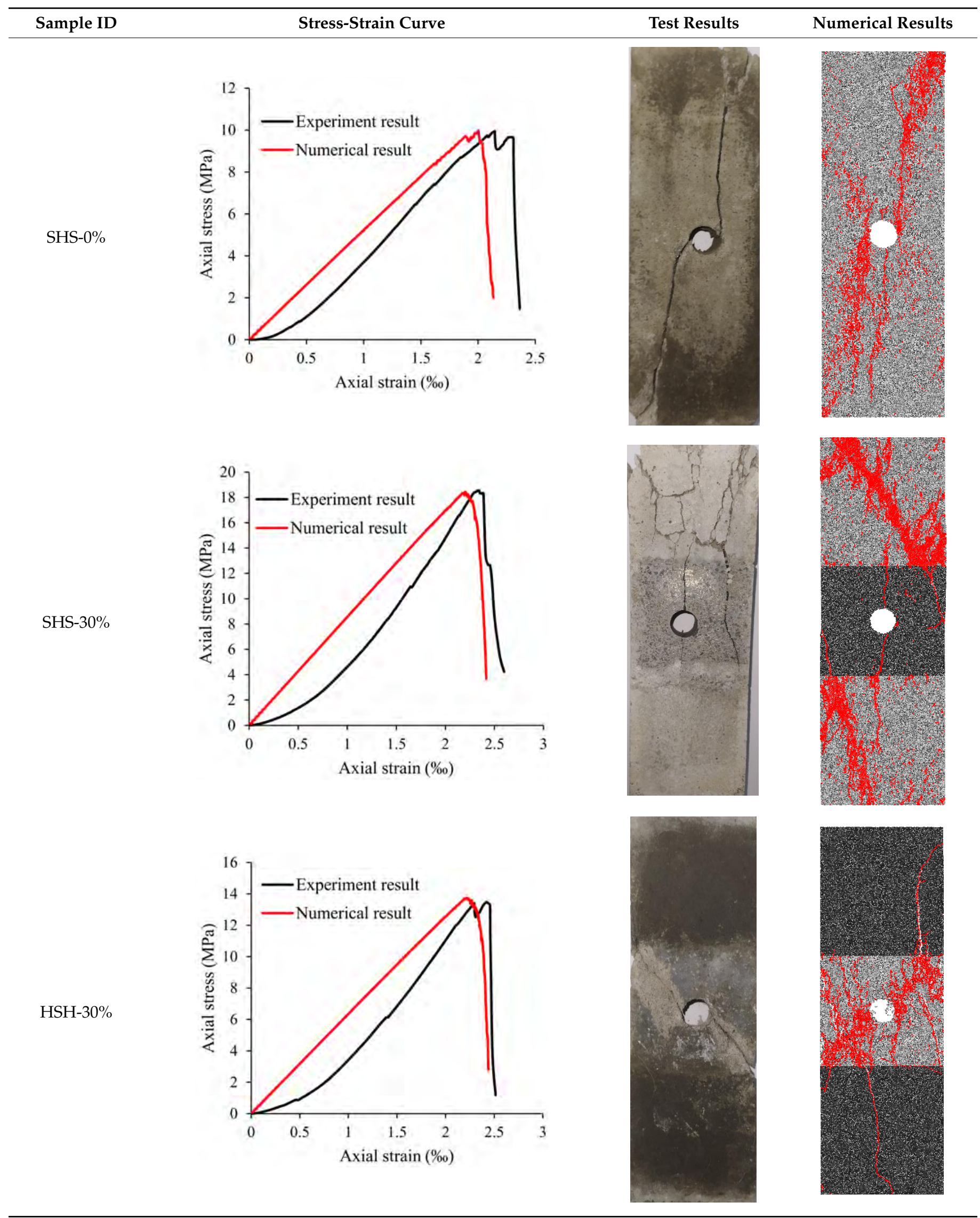


Table 4. Cont.

\begin{tabular}{llll}
\hline Sample ID & Test Results & Numerical Results \\
\hline Stress-Strain Curve & & & \\
\hline
\end{tabular}

\section{Results and Analysis}

\subsection{Analysis of the Mechanical Parameters of a Layered Rock Mass with a Single Hole}

Figure 4 shows the influence of interlayer height ratio on the peak strength and elastic modulus. Figure $4 \mathrm{a}$ shows that the peak strength of the HSH sample decreases with increasing height of the weak interlayer. When the height of the weak interlayer is $60 \%$ of the whole sample height, the peak strength of the sample tends to be stable with increasing height of the weak interlayer. In contrast, for SHS specimens, the peak strength increases with increasing hard interlayer height. When the hard interlayer height is $60 \%$ of the whole specimen height, the peak strength tends to be stable, with increasing weak interlayer height. Figure $4 \mathrm{~b}$ shows that for the HSH samples, the elastic modulus of the samples decreases approximately linearly with increasing height of the weak interlayer, while for the SHS samples, the elastic modulus of the samples increases approximately linearly with increasing height of the hard interlayer. It should be noted that the peak strength and elastic modulus of both the HSH and SHS specimens are between those of the pure hard rock specimen with a single hole and those of the pure soft rock specimen with a single hole when the interlayer is not zero. The holes, joints, strength and height of the interlayer have different degrees of influence on the mechanical properties of the rock specimen, and various factors interact with each other.

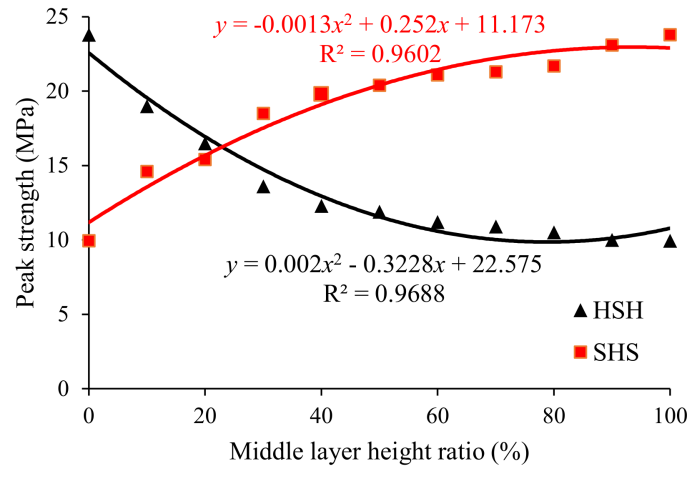

(a) Peak strength

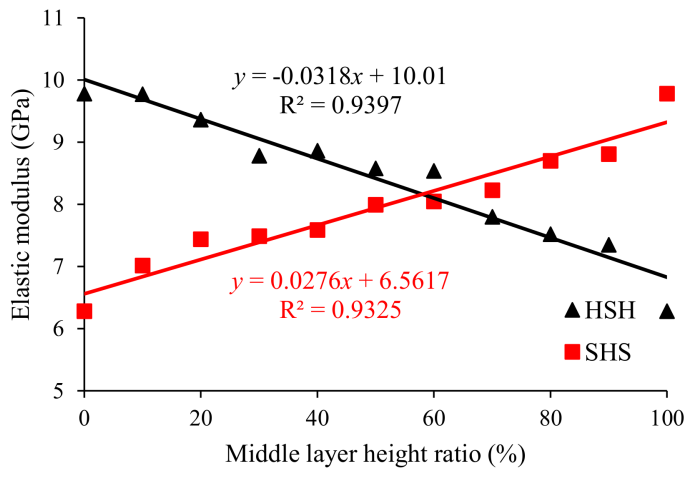

(b) Elastic modulus

Figure 4. Effect of the interlayer height ratio on the mechanical parameters of the specimens. 


\subsection{Analysis of the Failure Characteristics of a Layered Rock Mass with a Single Hole}

The key component of a crack initiation and propagation analysis in rock fracturing is the determination of the fracture criteria. Commonly used fracture criteria include: the maximum circumferential stress criterion, critical stress intensity factor criterion (fracture toughness $K_{C}$ ), maximum energy release rate criterion and strain energy density factor fracture criterion. Rock fracture is a type of sudden brittle failure. Griffith provided a fundamental description of this type of brittle fracture, wherein the growth of a propagating crack is caused by the crack driving force generated by the release of energy inside the body. The body simultaneously offers resistance crack growth. These two forces are balanced during the process of crack propagation; thus, when the crack driving force at the crack tip exceeds the resistance that prevents the crack surface from growing, a new crack surface forms, otherwise, the crack stops growing $[37,38]$.

Due to the focus on the failure mode of the surrounding rock around the hole, only the failure modes of the middle layers with hole are shown in Figure 5. The black ellipse indicates shear cracking, the yellow ellipse indicates tensile cracking, and the green ellipse indicates remote cracking. Figure 5a-d shows that with increasing height of the weak interlayer, the failure of the middle layer with holes changes from shear failure to tensionshear mixed failure. Figure $5 \mathrm{e}-\mathrm{h}$ show that with increasing height of the hard interlayer, the failure of the middle layer with holes changes from tensile failure to tension-shear mixed failure. It is worth noting that the probability of remote cracking is very low. The tensile cracks mainly initiate and propagate from the top and bottom of the hole, and the shear cracks mainly initiate and propagate from the left and right sides of the hole.

The above analysis shows that the failure process of layered rock masses with holes under a compressive loading is not a simple superposition of the failure due to the holes and layering, but is a coupled failure process and is affected by the height and strength of the intermediate interlayer. For the HSH specimens, when the interlayer is thin, the hard rock material with high strength limits the transverse deformation of the interlayer, which induces "three-dimensional" stress state in the weak interlayer, so it is difficult to produce tensile failure. However, with the increase in the height ratio of the intermediate weak layer, the influence of the hard rock components decreases, which makes the intermediate weak layer exhibit a mixed failure mode of tension and shear. For the SHS specimens, when the hard interlayer is thin, the soft rock with a lower strength promotes transverse deformation of the interlayer, resulting in tensile failure of the interlayer with holes. However, with the increase in the thickness ratio of the hard interlayer, the influence of the soft rock components decreases, which makes the hard interlayer with holes also present the mixed failure mode of tension and shear.

Here, the uniaxial compression tests and numerical simulations of layered rock samples with holes are carried out without considering the influence of confining pressure, which is inconsistent with the actual stress state of underground rock engineering projects such as tunnels. However, the test results are of great significance for analyzing the damage and failure of circular cross-section structures in layered rock and their later maintenance. The true triaxial testing and numerical simulation of layered rock samples with holes will be the next research direction. In addition, to simplify the factors affecting the test, the mechanical properties and failure modes of layered rock with holes are emphasized by the height and strength of the interlayer. Only two horizontal layered structures are considered. Considering the influence of bedding inclination on the mechanical properties and failure modes of layered composite rock samples with a single hole, this will be another important research direction. 


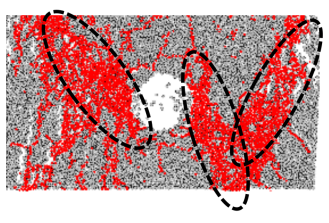

(a) $\mathrm{HSH}-20 \%$

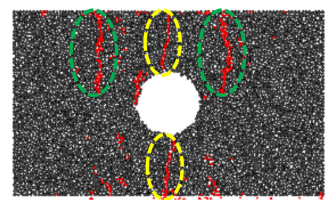

(e) SHS-20\%
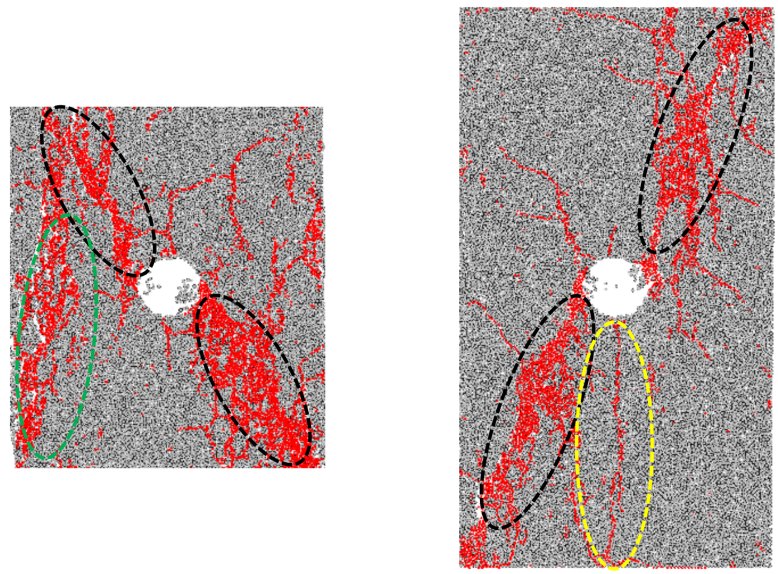

(c) $\mathrm{HSH}-60 \%$

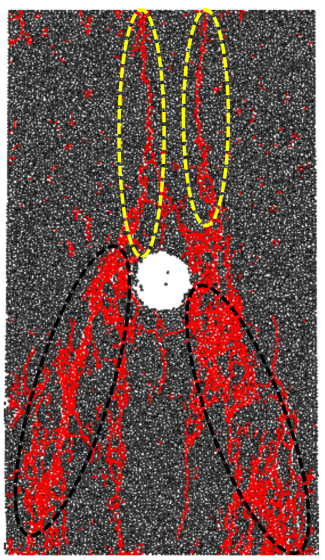

(g) SHS-60\%

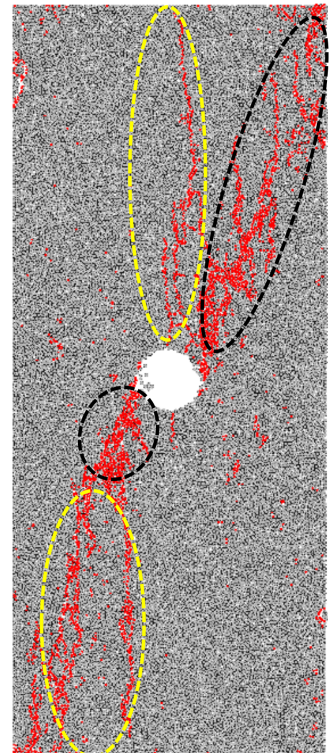

(d) $\mathrm{HSH}-80 \%$

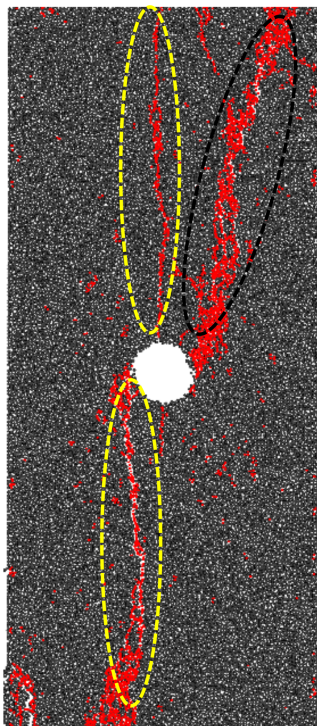

(h) $\mathrm{SHS}-80 \%$

Figure 5. Failure modes of HSH and SHS specimens.

Previous studies have shown that the process of crack initiation and propagation around the hole under load is complex, and produces many cracks. The crack location and mechanism can be used to generally classify into three forms [28]: (1) initial cracks (tensile cracks) in the tensile stress zone around the hole; (2) shear cracks in the compressive stress zone around the hole; and (3) remote crack in the rock mass far from the hole. The crack forms are shown in Figure 6. Dzik and Lajtai [39] studied the crack propagation law of granite with voids (radius 2.52 50 $\mathrm{mm}$ ) under uniaxial compression, and found that the three crack types do not necessarily appear simultaneously, that the crack form is related to the loading mode and the size of the voids, and that both the tensile stress and compressive stress have a considerable influence on initial crack initiation and propagation. 


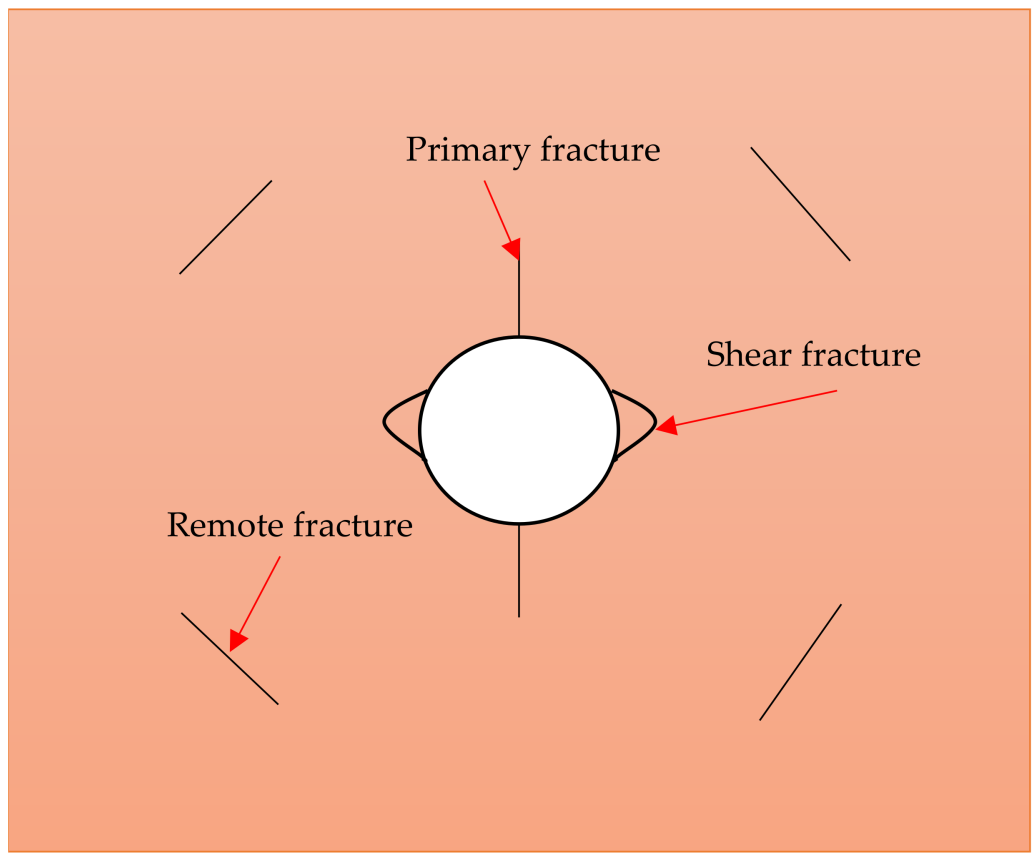

Figure 6. Types of fractures around circular openings.

\section{Discussion on the Crack Propagation Mechanism}

\subsection{Relationship between Crack Propagation and $A E$}

The AE of rock is directly related to the generation of micro-cracks in the rock. In PFC, the fracturing of a bond between particles will produce an AE event. With the built-in FISH language, the statistics of the number of fractured bonds between particles can be obtained, to realize the AE event simulation of rock [40]. That is, in PFC, the number of AEs at a certain time is the total number of cracks generated at this time minus the number of micro-cracks generated before this time. Taking sample $\mathrm{HSH}-50 \%$ as an example, the relationship between crack growth and $\mathrm{AE}$ evolution was discussed.

The relationship between the stress-strain curve and AE characteristics and the microcrack growth are shown in Figure 7. Figure 7a-e shows the six points where the stress-strain curve fluctuates greatly before and after the peak, respectively. The numbers marked in the micro-crack growth diagram represent the formation sequence of the macro-cracks.

Figure 7 shows that before the peak value of the stress-strain curve is reached, when the axial strain of the HSH-50\% sample reaches $0.925 \times 10^{-3}$, an AE event occurs in the sample. At this time, three tensile micro-cracks are generated in the sample, and the fluctuation phenomenon appears at point (a) on the stress-strain curve, corresponding to three tensile micro-cracks on the left side of the hole in Figure 7a. As the load on the specimen continues to increase, when the axial strain reaches $1.07 \times 10^{-3}$, some AE events occur. At this time, there are 13 tensile micro-cracks in the specimen, and the position of point (b) on the stress-strain curve also shows a wave phenomenon. Corresponding to Figure $7 \mathrm{~b}$, some tensile micro-cracks continue to appear on the right side of the hole. When the axial strain of the specimen reaches $1.67 \times 10^{-3}$, some AE events occur. At this time, 421 tensile micro-cracks and 10 shear micro-cracks are generated in the sample, and the position of point (c) on the stress-strain curve also shows a wave phenomenon, corresponding to that in Figure 7c, tensile crack 3 and tensile crack 4 are generated above and below the hole, and some micro-cracks are continuously generated near crack 1 and crack 2 , making crack 1 and crack 2 behave as macroscopic shear cracks. It is worth noting that crack 2 gradually changes from a shear crack to a tensile crack.

When the stress-strain curve reaches the (d) point after the peak stress, the axial strain of the sample reaches $2.08 \times 10^{-3}$, and some $\mathrm{AE}$ events occur. At this time, a total of 2480 tensile micro-cracks and 110 shear micro-cracks are generated in the sample, corresponding 
to the continuous propagation of crack 1 and crack 2 in Figure $7 \mathrm{~d}$, and shear crack 5 and tensile crack 6 are initiated in front of crack 2 . It should be noted that crack 3 and crack 4 hardly propagate during this process. When the axial strain of the specimen reaches $2.11 \times 10^{-3}$, some AE events occur. At this time, 3555 tensile micro-cracks and 140 shear micro-cracks are generated in the specimen, and the wave phenomenon also appears at point (e) on the stress-strain curve, corresponding to that in Figure 7e. Crack 6 continues to expand to the lower hard rock. It should be noted that during this process, crack 2 does not extend to the lower hard rock. When the axial strain of the specimen reaches $2.14 \times 10^{-3}$, some AE events occur. At this time, 5635 tensile micro-cracks and 178 shear micro-cracks are generated in the specimen. The position of point (f) on the stress-strain curve also varies, corresponding to the continuous propagation of crack 1 and crack 6 in Figure $7 f$.

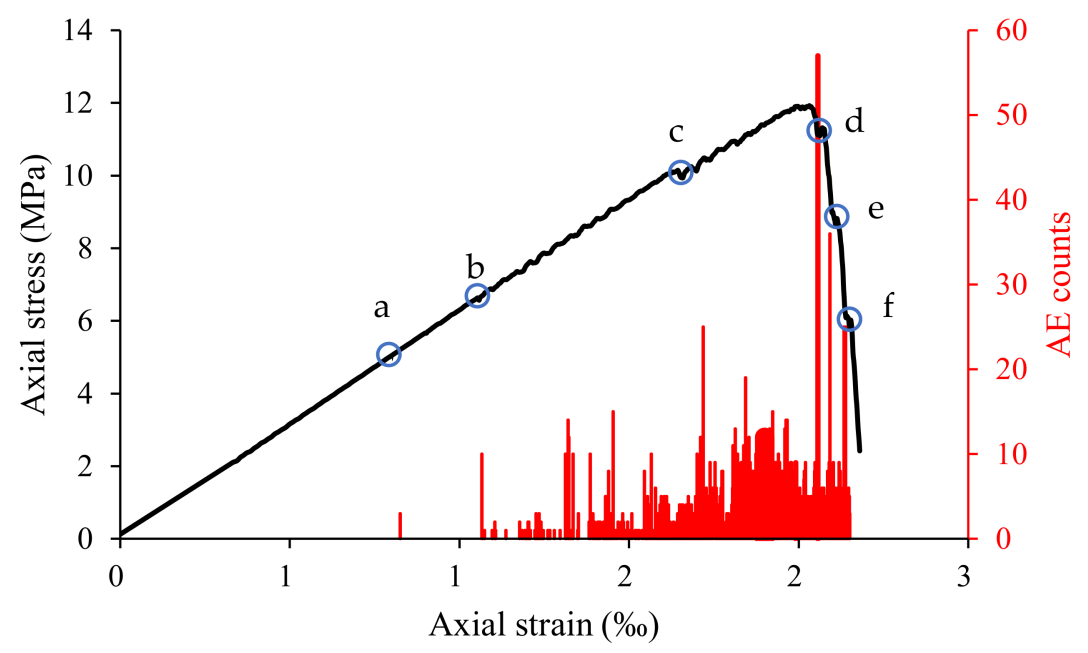

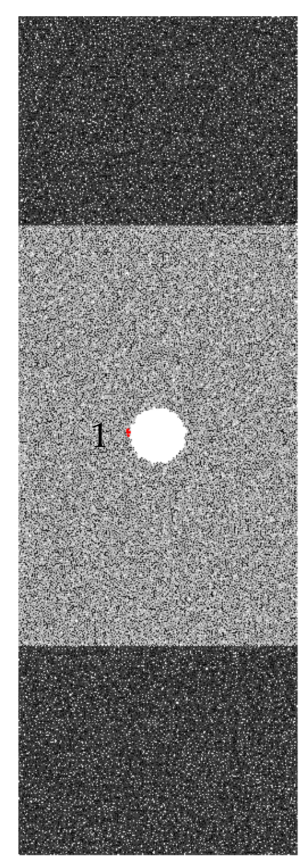

(a) Axial strain $0.925 \times 10^{-3}$

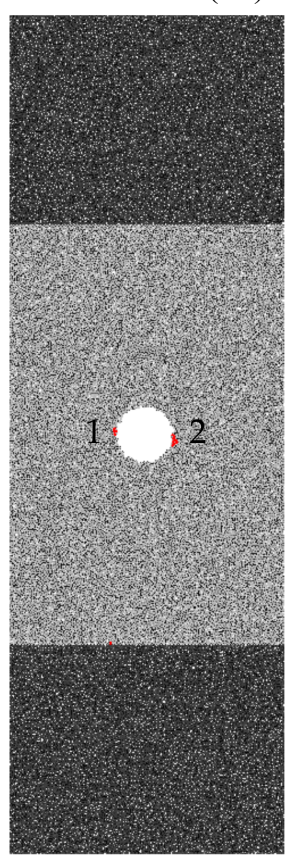

(b) Axial strain $1.07 \times 10^{-3}$

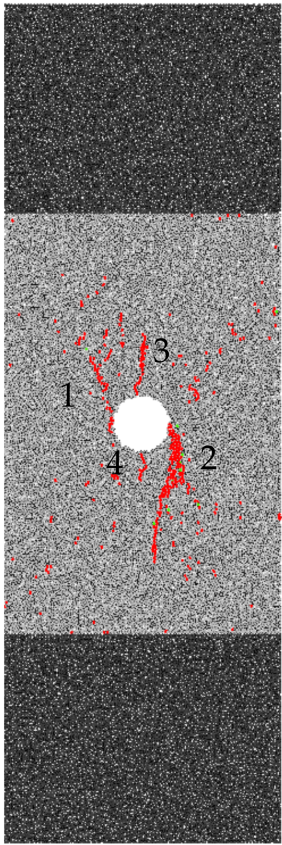

(c) Axial strain $1.67 \times 10^{-3}$

Figure 7. Cont. 


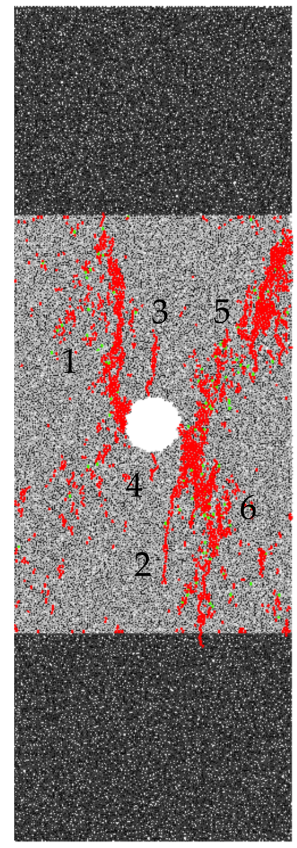

(d) Axial strain $2.08 \times 10^{-3}$

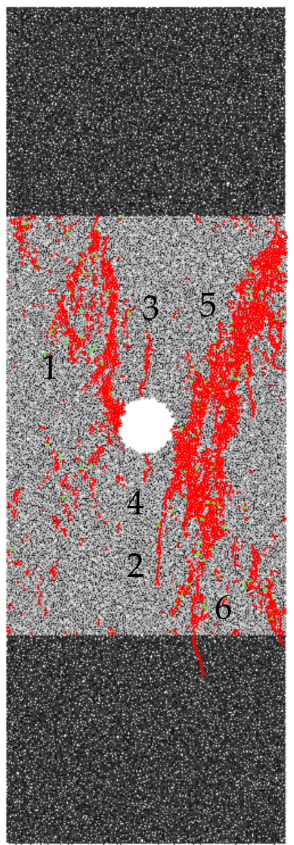

(e) Axial strain $2.11 \times 10^{-3}$

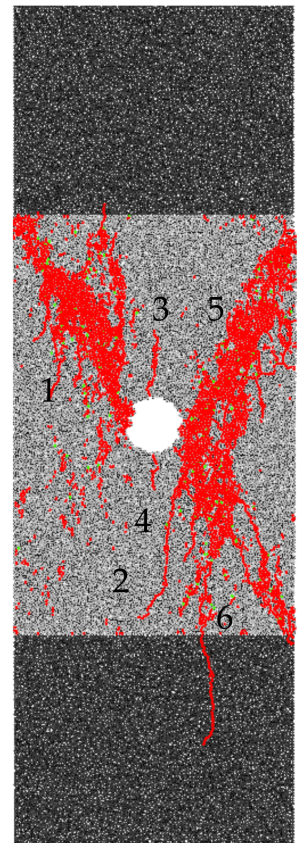

(f) Axial strain $2.14 \times 10^{-3}$

Figure 7. Relationship between the stress-strain curve and AE behavior (HSH-50\%).

From the above analysis, it was determined that a total of 5813 micro-cracks were generated under the uniaxial loading, of which tensile micro-cracks accounted for $96.94 \%$ and shear micro-cracks accounted for $3.06 \%$. At the microscale, the specimen mainly exhibited tensile failure, while at the macroscale, the main failure of the weak interlayer in the middle of the specimen was due to shear crack 1 , shear crack 5 and tensile crack 6. Notably, the compressive strength of rock materials is much higher than their tensile strength, and tensile failure occurs more between particles under an external load.

\subsection{Relationship between the Crack Growth Process and Stress Field}

Figure 8 shows the evolution of the parallel bond force between particles before and after the initiation of specimen HSH-50\% initial cracks (i.e., cracks 1, 2, 3 and 4 in Figure 7). The parallel bond force in the figure is represented by line segments, among which red represents the cracks, green represents the tensile force, and black represents the pressure force. The thickness of the line segment is proportional to the force. As shown in Figure 8, a tensile stress concentration area forms at the upper and lower edges of the hole, and a compressive stress concentration area forms at the left and right edges. Then, tensile micro-cracks are generated in the tensile stress concentration area, and the micro-cracks aggregate to form macro-cracks. Comparing the stress field changes before and after crack initiation in the sample, it can be seen that the stress concentration area is first generated in a certain area of the sample. When the stress increases to a certain extent, the bond between particles is broken, and micro-cracks are generated. With the initiation of micro-cracks, the stress concentration region disappears in this region and transfers to the next region. In the process of stress concentration area transfer, new micro-cracks are continuously initiated, and micro-cracks converge to form macro-cracks. This is why the tensile cracks mainly originate from the upper and lower edges of the hole, while the shear cracks mainly originate from the left and right sides of the hole.

\subsection{Relationship between the Crack Growth Process and Number of Micro-cracks}

PFC can record the position and number of micro-cracks that form during the simulation process. The relationship between the SHS-30\% stress-strain curve and the number of micro-cracks is shown in Figure 9. Points (a), (b) and (c) in the figure represent the pre-peak, 
peak and post-peak stress points respectively, and the corresponding macro-failure modes of points (a), (b) and (c) are given.

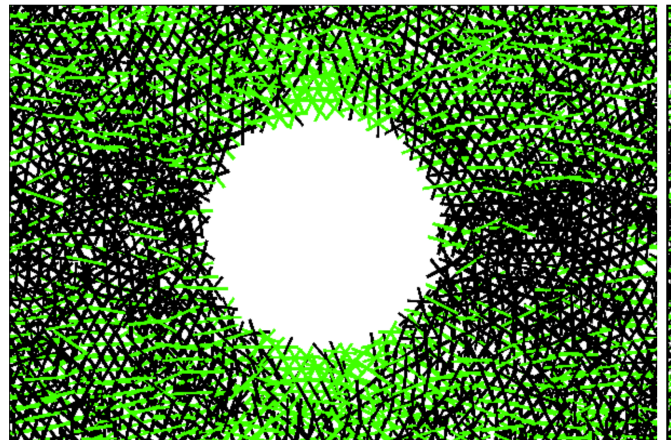

(a) Before initial crack formation

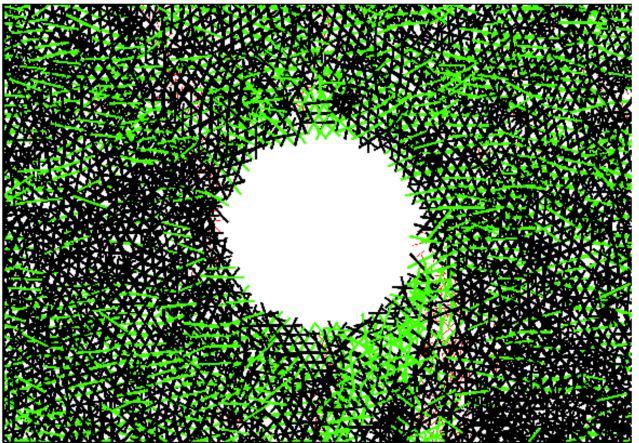

(b) After initial crack formation

Figure 8. Distribution of parallel bond forces during crack propagation (HSH-50\%).

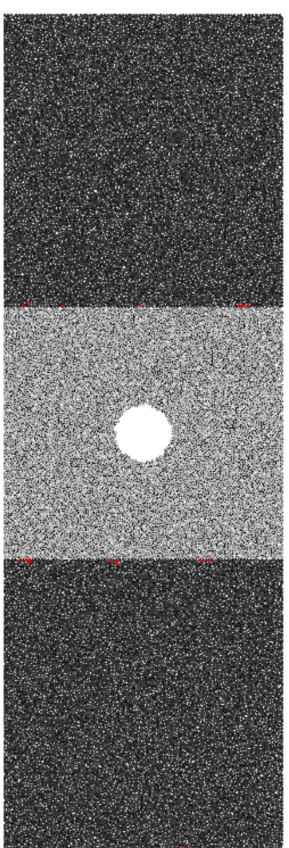

(a) Pre-peak stress point 离

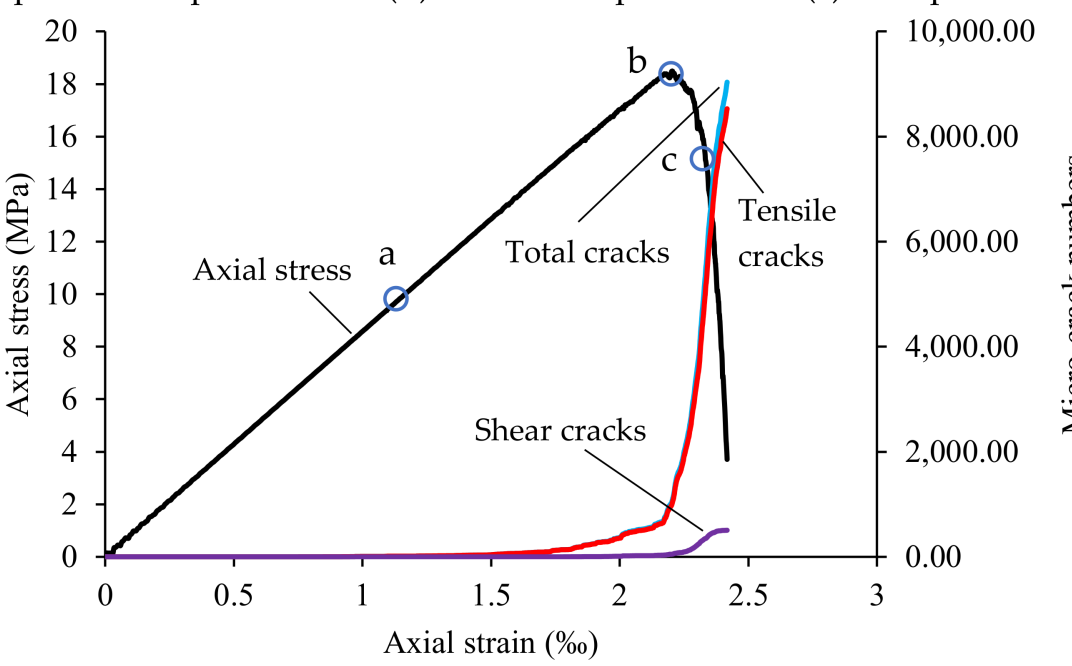

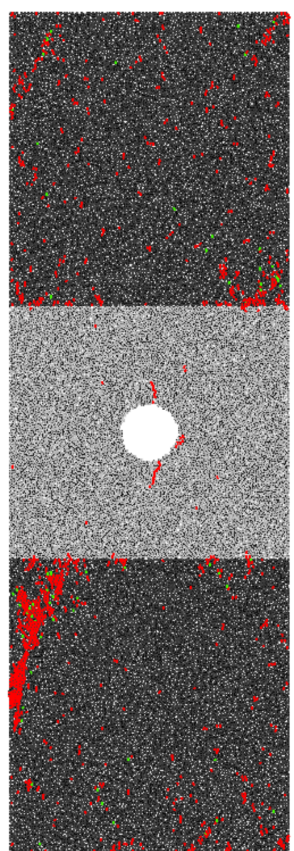

(b) Peak stress point

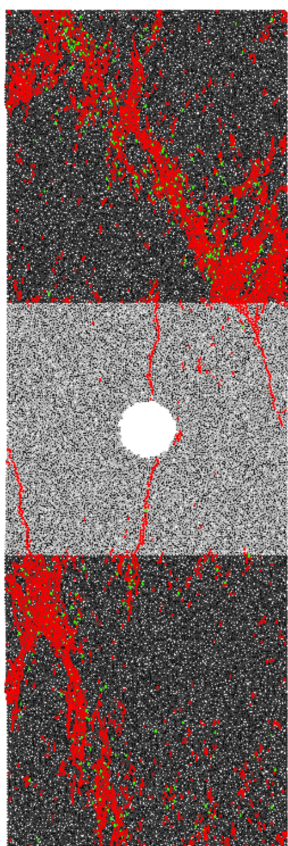

(c) Post-peak stress point

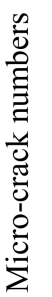

Figure 9. Relationship between the stress-strain curve and number of microcracks (SHS-30\%). 
In the pre-peak elastic deformation stage, the SHS-30\% samples produce fewer cracks. For example, at a point before the peak, the corresponding stress is 8.29 MPa. At this time, there are 21 micro-cracks in the sample, including 21 tensile and 0 shear micro-cracks. However, with the increase in deformation, the propagation of micro-cracks becomes faster. When the stress reaches the peak strength of $18.78 \mathrm{MPa}$, that is, point (b) on the curve, 1132 micro-cracks are generated, including 1079 and 53 tensile and shear microcracks, respectively. In the post-peak stage, the total number of micro-cracks in the sample increases sharply. For example, at point (c), the corresponding stress is $14.14 \mathrm{MPa}$, and a total of 6855 micro-cracks are generated, including 6409 and 446 tensile and shear microcracks, respectively. The number of tensile micro-cracks is much larger than the number of shear micro-cracks, which indicates that the specimen mainly experiences tensile failure under uniaxial compression.

Figure 10 depicts the effect of the interlayer height on the number of micro-cracks in the horizontally layered rock samples with voids. The number of shear micro-cracks is far less than the number of tensile micro-cracks in both the HSH and SHS specimens. The number of micro-cracks in an SHS sample is greater than that in the corresponding HSH sample, which indicates that the damage degree of an SHS sample is higher than that of the corresponding HSH sample.

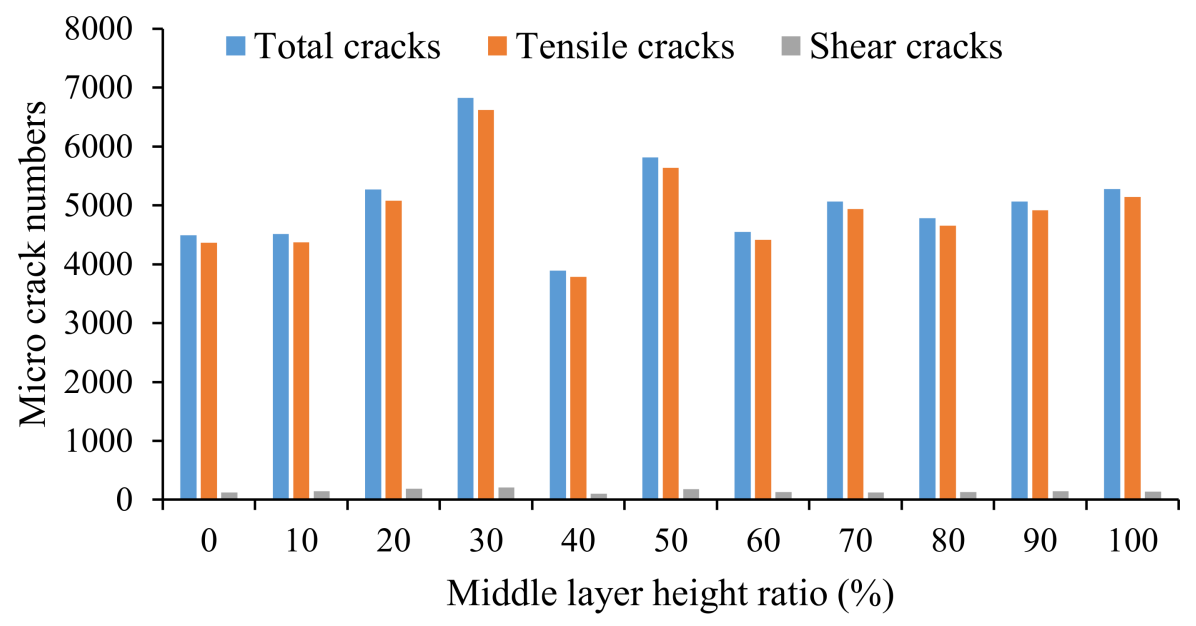

(a) $\mathrm{HSH}$

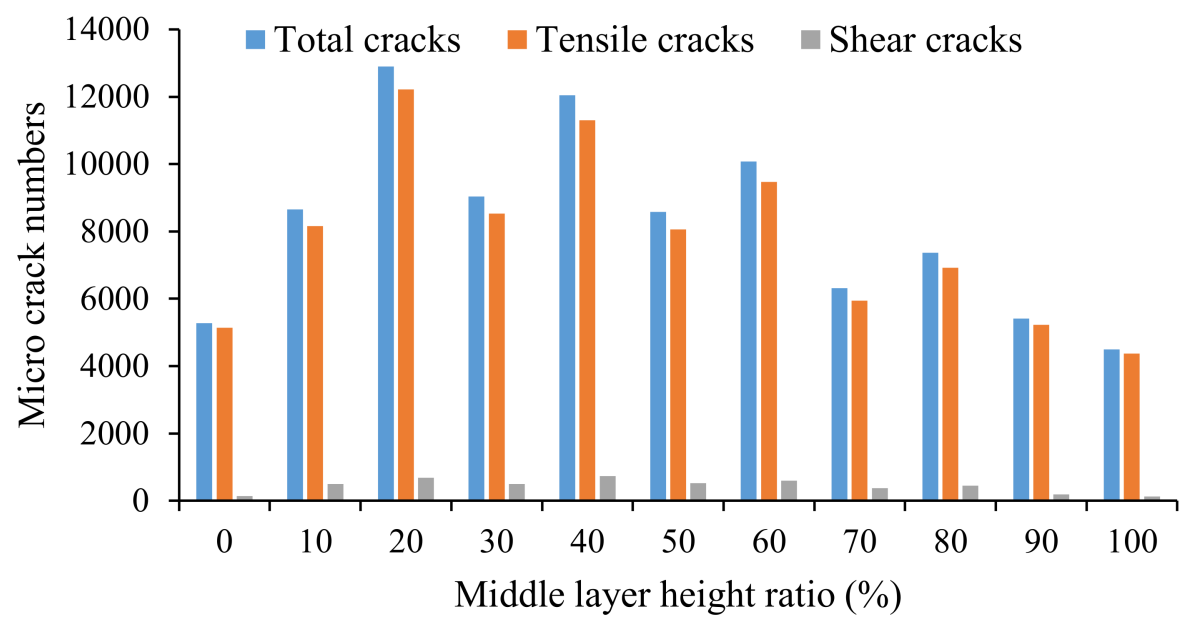

(b) SHS

Figure 10. Effect of the interlayer height on the number of microcracks in horizontally layered specimens with holes. 


\section{Conclusions}

In this paper, the mechanical properties and failure mechanism of layered rock samples with holes are studied by uniaxial compression tests and numerical simulations. The effects of the height ratio and strength of the interlayer on the mechanical properties and failure mode of the layered rock samples with holes are mainly studied. The conclusions are as follows:

(1) The peak strength of the HSH specimens decreases nonlinearly and monotonically with the increasing interlayer height ratio, and the elastic modulus decreases linearly with the increasing height ratio of the interlayer; however, the SHS specimen results the opposite trends. However, the peak strength and elastic modulus of the HSH and SHS samples are between those of the pure hard rock with a single hole and the pure soft rock with a single hole.

(2) With the increase in the height ratio of the interlayer, the failure mode of the $\mathrm{HSH}$ samples with holes changes from shear failure to tension-shear mixed failure, and that of the SHS samples with holes changes from tensile failure to tension-shear mixed failure. The failure mode of the pure hard and pure soft rock samples with holes is shear failure diagonally across the samples. The tensile cracks in the middle interlayers initiate and propagate from the top and bottom of the hole, while the shear cracks mainly initiate and propagate from the left and right sides of the hole.

(3) The results of the AE events, stress fields and micro-crack evolution reveal the crack propagation mechanism of layered rock samples with holes. First, a stress concentration zone is formed at the edge of the hole. With increasing stress, the bond between particles is broken, resulting in the formation of micro-cracks and initiation of AE events in the sample. With the increase in stress and the evolution of the stress field, the number of micro-cracks increases gradually, and the number of AE events in the sample also increases. Finally, the micro-cracks gradually expand to form macro-cracks, which cause the sample to fracture. In the simulation, significantly more tensile micro-cracks than shear micro-cracks formed.

Author Contributions: Conceptualization, G.W., Y.W., H.S., and G.Y.; Data curation, G.W., Y.W., H.S., and G.Y.; Formal analysis, G.W., Y.W., H.S., and G.Y.; Funding acquisition, L.S., M.Z., Q.X., G.X., W.Z., and J.G.; Investigation, L.S., M.Z., Q.X., G.X., W.Z., and J.G.; Methodology, G.W., Y.W., H.S., and G.Y.; Project administration, L.S., M.Z., Q.X., G.X., W.Z., and J.G.; Resources, L.S., M.Z., Q.X., G.X., W.Z., and J.G.; Software, G.W., Y.W., H.S., and G.Y.; Supervision, L.S.; Validation, G.W., Y.W., H.S., G.Y., L.S., M.Z., Q.X., G.X., W.Z., and J.G.; Visualization, G.W., Y.W., H.S., G.Y., L.S., M.Z., Q.X., G.X., W.Z., and J.G.; Writing—original draft, G.W.; Writing—review \& editing, G.W., Y.W., H.S., G.Y., L.S., and M.Z. All authors have read and agreed to the published version of the manuscript.

Funding: Financial supports for this work, provided by the Fundamental Research Funds for the Central Universities (2018ZDPY08) and the National Natural Science Foundation of China (41474122, 41974164, 51323004), are gratefully acknowledged.

Institutional Review Board Statement: Not applicable.

Informed Consent Statement: Not applicable.

Data Availability Statement: The data used to support the findings of this study are available from the corresponding author upon request.

Conflicts of Interest: The authors declare no conflict of interest.

\section{References}

1. Wen, S.; Zhang, C.S.; Chang, Y.L.; Hu, P. Dynamic compression characteristics of layered rock mass of significant strength changes in adjacent layers. J. Rock Mech. Geotech. Eng. 2020, 12, 353-365. [CrossRef]

2. Huang, D.M.; Chang, X.K.; Tan, Y.L.; Zhou, J.H.; Yin, Y.C. Numerical Study of the Mechanical and Acoustic Emissions Characteristics of Red Sandstone under Different Double Fracture Conditions. Symmetry 2019, 11, 772. [CrossRef]

3. Xie, H.P.; Liu, J.F.; Ju, Y.; Li, J.; Xie, L.Z. Fractal property of spatial distribution of acoustic emissions during the failure process of bedded rock salt. Int. J. Rock. Mech. Min. Sci. 2011, 48, 1344-1351. [CrossRef]

4. Aksoy, C.O.; Kantarci, O.; Ozacar, V. An example of estimating rock mass deformation around an underground opening using numerical modeling. Int. J. Rock. Mech. Min. Sci. 2010, 47, 272-278. [CrossRef] 
5. Yang, X.W.; Zhang, X.P.; Zhang, Q.; Li, C.D.; Wang, D.J. Study on the mechanisms of crack turning in bedded rock. Eng. Fract. Mech. 2021, 247, 107630. [CrossRef]

6. Stephansson, O. Stability of single openings in horizontally bedded rock. Eng. Geol. 1971, 5, 5-17. [CrossRef]

7. Jaeger, J.C. Shear failure of anistropic rocks. Geol. Mag. 1960, 97, 65-72. [CrossRef]

8. Tien, Y.M.; Kuo, M.C. A failure criterion for transversely isotropic rocks. Int. J. Rock. Mech. Min. Sci. 2001, 35, 399-412. [CrossRef]

9. Saeidi, O.; Rasouli, V.; Vaneghi, R.G.; Gholami, R.; Torabi, S.R. A modified failure criterion for transversely isotropic rocks. Geosci. Front. 2014, 5, 215-225. [CrossRef]

10. Tien, Y.M.; Kuo, M.C.; Juang, C.H. An experimental investigation of the failure mechanism of simulated transversely isotropic rocks. Int. J. Rock. Mech. Min. Sci. 2006, 43, 1163-1181. [CrossRef]

11. Zhang, G.M.; Li, Y.P.; Yang, C.L.; Liu, W.; Shi, X.L.; Yang, C.H. Physical simulation of the deformation and failure mechanism of soft and hard interbedded salt rocks. Chin. J. Rock Mech. Eng. 2012, 31, 1813-1820.

12. Liu, X.Y.; Ma, L.J.; Ma, S.N.; Zhang, X.W.; Gao, L. Comparative study of four failure criteria for intact bedded rock salt. Int. J. Rock. Mech. Min. Sci. 2011, 48, 341-346. [CrossRef]

13. Qiu, J.D.; Li, D.Y.; Li, X.B.; Zhou, Z.L. Dynamic Fracturing Behavior of Layered Rock with Different Inclination Angles in SHPB Tests. Shock Vib. 2017, 2017, 7687802. [CrossRef]

14. Xu, D.P.; Gu, G.K.; Wang, L.P.; Chen, D.F.; Huang, S.L. An Index for Estimating the Stability of the Layered Rock Masses under Excavation Disturbance. Avd. Mater. Sci. Eng. 2018, 2018, 1761895. [CrossRef]

15. Parsamehr, H.; Mohammadi, S.D.; Moarefvand, P. Numerical modeling of wellbore stability in layered rock masses. Arab. J. Geosci. 2015, 8, 10845-10858. [CrossRef]

16. Wasantha, P.L.P.; Ranjith, P.G.; Shao, S.S. Energy monitoring and analysis during deformation of bedded-sandstone: Use of acoustic emission. Ultrasonics 2014, 54, 217-226. [CrossRef]

17. Wang, H.; Ren, F.Q.; Chang, Y. Effect of bedding angle on tunnel slate failure behavior under indirect tension. Geomat. Nat. Haz. Risk 2020, 11, 428-445. [CrossRef]

18. Wu, B.; Huang, W. Uniaxial Compression Mechanical Properties of Rock Samples in Soft and Hard Composite Strata. Adv. Mater. Sci. Eng. 2020, 2020, 5920348. [CrossRef]

19. Cheng, J.L.; Yang, S.Q.; Chen, K.; Ma, D.; Li, F.Y.; Wang, L.M. Uniaxial experimental study of the acoustic emission and deformation behavior of composite rock based on 3D digital image correlation (DIC). Acta Mech. Sin. 2017, 33, 999-1021. [CrossRef]

20. Duveau, D.; Shao, J.F. A modified single plane of weakness theory for the failure of highly stratified rocks. Int. J. Rock. Mech. Min. Sci. 1998, 35, 807-813. [CrossRef]

21. Nasseri, M.H.B.; Rao, K.S.; Ramamurthy, T. Anisotropic strength and deformational behavior of Himalayan schists. Int. J. Rock. Mech. Min. Sci. 2003, 40, 3-23.

22. Zhang, X.M.; Feng, Y.; Yang, J.S. Experimental Study on Anisotropic Strength Properties of Sandstone. Electron. J. Geotech. Eng. 2010, 15, 1325-1335.

23. Xu, L.R.; Huang, Y.Y.; Rosakis, A.J. Dynamic crack deflection and penetration at interfaces in homogeneous materials: Experimental studies and model predictions. J. Mech. Phys. Solids 2003, 51, 461-486.

24. Sammis, C.G.; Ashby, M.F. The failure of brittle porous solids under compressive stress states. Acta Metall. 1986, 34, 511-526. [CrossRef]

25. Carranaza-Torres, C.; Fairhurst, C. Application of the Convergence-Confinement method of tunnel design to rock masses that satisfy the Hoek-Brown failure criterion. Tunn. Undergr. Space Technol. 2000, 15, 187-213. [CrossRef]

26. Unlu, T.; Gercek, H. Effect of Poisson's ratio on the normalized radial displacements occurring around the face of a circular tunnel. Tunn. Undergr. Space Technol. 2003, 15, 547-553. [CrossRef]

27. Lajtai, E.Z.; Lajtai, V.N. The collapse of cavities. Int. J. Rock Mech. Min. Sci. 1975, 12, 81-86. [CrossRef]

28. Carter, B.J.; Lajtai, E.Z.; Petukhov, A. Primary and remote fracture around underground cavities. Int. J. Numer. Anal. Methods Geomech. 1991, 15, 21-40. [CrossRef]

29. Wong, R.H.C.; Lin, P.; Tang, C.A. Experimental and numerical study on splitting failure of brittle solids containing single pore under uniaxial compression. Mech. Mater. 2006, 38, 142-159. [CrossRef]

30. Li, D.Y.; Zhou, Q.Q.; Zhou, Z.L.; Li, X.B.; Ranjith, P.G. Fracture analysis of marble specimens with a hole under uniaxial compression by digital image correlation. Eng. Fract. Mech. 2017, 183, 109-124. [CrossRef]

31. Wu, H.; Zhao, G.Y.; Liang, W.Z. Investigation of cracking behavior and mechanism of sandstone specimens with a hole under compression. Int. J. Mech. Sci. 2018, 163, 105084. [CrossRef]

32. Cundall, P.A.; Strack, O.D.L. A discrete numerical model for granular assemblies. Geotechnique 1979, 29, 47-65. [CrossRef]

33. Cho, N.; Martin, C.D.; Sego, D.C. A clumped particle model for rock. Int. J. Rock. Mech. Min. Sci. 2007, 44, 997-1010. [CrossRef]

34. Ministry of Water Resources of the People's Republic of China. B/T 50218-2014 Standard for Engineering Classification of Rock Mass; China Standard Press: Beijing, China, 2015.

35. Shi, H.; Song, L.; Zhang, H.Q.; Xue, K.K.; Yuan, G.T.; Wang, Z.S.; Wang, G.Z. Numerical study on mechanical and failure properties of sandstone based on the power-law distribution of pre-crack length. Geomech. Eng. 2019, 19, 421-434.

36. Shi, H.; Zhang, H.Q.; Song, L. Evolution of sandstone shear strength parameters and its mesoscopic mechanism. Geomech. Eng. 2020, 20, 29-41. 
37. Khodadadian, A.; Noii, N.; Parvizi, M.; Abbaszadeh, M.; Wick, T.; Heitzinger, C. A Bayesian estimation method for variational phase-field fracture problems. Comput. Mech. 2020, 66, 827-849. [CrossRef]

38. Aldakheel, F.; Noii, N.; Wick, T.; Wriggers, P. A global-local approach for hydraulic phase-field fracture in poroelastic media. Comput. Math. Appl. 2021, 91, 99-121. [CrossRef]

39. Dzik, E.J.; Lajtai, E.Z. Primary fracture propagation from circular cavities loaded in compression. Int. J. Fract. 1992, 57, 221-236. [CrossRef]

40. Cundall, P.A. Particle Flow Code in 2 Dimensions Command and Fish Reference Summary; Itasca Consulting Group Inc.: Minneapolis, MN, USA, 1999. 